\title{
Crescimento, produtividade e coloração dos chips de tubérculos de batata produzidos sob alta disponibilidade de potássio
}

\author{
Growth, yield and chip color of potato tubers grown under high potassium availability
}

\author{
Clarissa Melo Cogo ${ }^{1}$ Jerônimo Luiz Andriolo ${ }^{2}$ Dilson Antônio Bisognin ${ }^{3}$ Rodrigo dos Santos Godoi ${ }^{4}$ \\ Orcial Ceolin Bortolotto $^{4}$ Gisele Teixeira Barros ${ }^{4}$
}

\begin{abstract}
O objetivo do trabalho foi quantificar o crescimento e a produtividade e avaliar a coloração de chips de tubérculos da cv. Asterix de batata produzidos sob alta disponibilidade de potássio. O experimento foi conduzido no Departamento de Fitotecnia da UFSM, RS, em abrigo telado de $200 \mathrm{~m}^{2}$, no período entre 28/08/2004 e 30/11/2004. Foram empregadas sacolas de polietileno contendo $1,4 \mathrm{~kg}$ de substrato orgânico (Plantmax $\left.{ }^{\circledR}\right)$, com um tubérculo por sacola. Os teores disponíveis de nutrientes contidos no substrato foram de 95; 1.506; 7.831 e $2.948 \mathrm{mg} \mathrm{kg}^{-1}$ de $\mathrm{P}, \mathrm{K}$, Ca e $\mathrm{Mg}$, respectivamente. Os cinco tratamentos consistiram de doses suplementares de $\mathrm{K}$ fornecidas diariamente por fertirrigação, através de cinco soluções nutritivas contendo 3,$5 ; 5,5 ; 6,5 ; 8,0$ e 9,5mmol $L^{-1}$ de $K$. As quantidades totais de $K$ disponibilizadas em cada sacola através das soluções nutritivas ao longo do período experimental foram de 912,3; 1.433,7; 1.694,3; 2.085,3 e $2.476,3 \mathrm{mg}$ por planta, respectivamente.O crescimento da área foliar das plantas aumentou linearmente com a disponibilidade de K. Não foram observados efeitos significativos sobre o número, a massa seca e a produtividade de tubérculos e a qualidade dos chips. Níveis elevados de adubação potássica não exercem efeito depressivo na produtividade de tubérculos e na qualidade dos chips de batata.
\end{abstract}

Palavras-chave: Solanum tuberosum, fertirrigação, solução nutritiva, massa seca.

\section{ABSTRACT}

The objective was to verify the effect of high potassium availability on plant growth and tuber yield and chip color of potato, cv. Asterix. The experiment was conducted in a $200 \mathrm{~m}^{2}$ polyethylene greenhouse at the Departamento de Fitotecnia, UFSM, from August, 28 to November, 30, 2005. Polyethylene bags were filled with $4 \mathrm{dm}^{3}$ of organic substrate (Plantmax ${ }^{\circledR}$ ) and one tuber was planted. The P, K, Ca and $\mathrm{Mg}$ availabilities were 95; 1,506; 7,831 and 2,948mg $\mathrm{kg}^{-1}$, respectively. Plants were daily fertigated with nutrient solutions containing supplementary $K$ doses of $3.5 ; 5.5 ; 6.5 ; 8.0$ and $9.5 \mathrm{mmol} \mathrm{L}^{-1}$. Potassium available in each bag during the experimental period was $912.3 ; 1,433.7 ; 1,694.3 ; 2,085.3 e$ $2,476.3 \mathrm{mg}$ per plant, respectively. The leaf area index increased with $K$ availability. There were no effect on tuber number, dry mass and yield and chip color. High $K$ fertilization rates does not affect tuber yield and chip color of potato.

Key words: Solanum tuberosum, fertigation, nutrient solution, dry mass.

A exportação de $\mathrm{K}$ do solo pela cultura da batata é de aproximadamente 1,5 vezes superior a de $\mathrm{N}$ e de 4 a 5 vezes a de P (YORINORI, 2003). A recomendação de adubação potássica para uma produtividade estimada acima de $20 \mathrm{tha}^{-1}$ varia de $140 \mathrm{a}$ $220 \mathrm{~g} \mathrm{ha}^{-1} \mathrm{de}_{2} \mathrm{O}$ entre as classes de interpretação muito alto e muito baixo, respectivamente (COMISSÃO DE QUÍMICA E FERTILIDADE DO SOLO, 2004). Dependendo da classe de solo e de regime hídrico, as perdas por lixiviação podem ser reduzidas e o acúmulo no solo pode ocorrer após cultivos sucessivos, quando

\footnotetext{
${ }^{1}$ Programa de Pós-graduação em Agronomia (PPGA), Universidade Federal de Santa Maria (UFSM), 97105-900, Santa Maria, RS, Brasil.

${ }^{2}$ Departamento de Fitotecnia, UFSM, 97105-900, Santa Maria, RS, Brasil. E-mail: andriolo@smail.ufsm.br. Autor para correspondência.

${ }^{3}$ Departamento de Fitotecnia, UFSM, 97105-900, Santa Maria, RS, Brasil.

${ }^{4}$ Curso de Agronomia da UFSM, 97105-900, Santa Maria, RS, Brasil.
} 
as doses aplicadas ultrapassam as quantidades exportadas pela cultura. Essa possibilidade existe nos solos da região Sul do Brasil, onde é realizado o cultivo bianual da batata. Tais solos são naturalmente ricos em $\mathrm{K}$, com níveis que podem interferir no crescimento e na produtividade da cultura, devido a distúrbios nutricionais decorrentes dos antagonismos entre cátions, especialmente o $\mathrm{Ca}^{++}$e o $\mathrm{Mg}^{++}$(ABDELGADIR et al., 2003).

O objetivo deste trabalho foi, portanto, determinar o efeito de níveis elevados de adubação potássica no crescimento, produtividade e coloração dos chips de tubérculos de batata da cultivar Asterix.

$\mathrm{O}$ experimento foi conduzido no Departamento de Fitotecnia da UFSM, Santa Maria, em abrigo telado com $200 \mathrm{~m}^{2}$ de área. O plantio foi feito em 28/08/2004, em sacolas de polietileno contendo 1,4kg de substrato orgânico (Plantmax ${ }^{\circledR}$ ), com um tubérculo da cultivar Asterix em cada sacola, na densidade de 4,4plantas $\mathrm{m}^{-2}$. A análise química do substrato indicou teores disponíveis de 95; 1.506; 7.831 e $2.948 \mathrm{mg} \mathrm{kg}^{-1}$ de $\mathrm{P}, \mathrm{K}, \mathrm{Ca}$ e Mg, respectivamente. Os tratamentos foram constituídos por cinco soluções nutritivas com concentrações de potássio de 3,5; 5,5; 6,5; 8,0 e 9,5mmol $\mathrm{L}^{-1}$, respectivamente para $\mathrm{T} 1, \mathrm{~T} 2, \mathrm{~T} 3, \mathrm{~T} 4 \mathrm{e}$ T5. Os demais nutrientes foram fornecidos nas concentrações de 13,0 de $\mathrm{NO}_{3}^{-} / \mathrm{NH}_{4}^{+} ; 2,0$ de $\mathrm{H}_{2} \mathrm{PO}_{4}^{-} ; 1,0$ de $\mathrm{SO}_{4}^{--} ; 1,0 \mathrm{de} \mathrm{Mg}^{++}$; 4,0 $\mathrm{mmol} \mathrm{L}^{-1} \mathrm{de} \mathrm{Ca}^{++}$e de 0,03 de Mo; 0,26 de B; 0,06 de $\mathrm{Cu}, 0,50$ de $\mathrm{Mn}, 0,22$ de $\mathrm{Zn}$ e 4,0mg $\mathrm{L}^{-1}$ de Fe, com condutividade elétrica de 1,7; 1,87; 2,19; 2,51 e 2,72dS m ${ }^{-1}$, respectivamente. Empregou-se um gotejador de vazão igual a $1,4 \mathrm{~L} \mathrm{~h}{ }^{-1}$ para cada sacola e um coeficiente de drenagem de $20 \%$. A freqüência das fertirrigações foi determinada com base na demanda hídrica da cultura, estimada por unidade de radiação solar e de área foliar de hortaliças cultivadas no mesmo local, em ambiente protegido (DALSASSO et al., 1997). O volume de solução nutritiva fornecida para cada planta no decorrer do período experimental totalizou 6,7L, correspondendo a 912,3; 1.433,7; 1.694,3; 2085,3 e 2476,3mg de K para cada tratamento. Foi empregado o delineamento experimental inteiramente casualizado com três repetições de 25 sacolas. O experimento foi encerrado aos 73 dias após o plantio, quando da senescência das plantas. Imediatamente após a coleta, foram separados os limbos foliares, hastes e tubérculos, sendo pesados para determinação da massa fresca e seca, em estufa de circulação forçada de ar, na temperatura de $60^{\circ} \mathrm{C}$, até massa constante. Aárea foliar específica de cada planta coletada foi determinada através da massa seca de 30 discos de $1 \times 10^{-4} \mathrm{~m}^{2}$ de diâmetro. Uma relação foi estabelecida entre a massa seca e a superfície dos discos, a qual foi empregada para estimar o índice de área foliar da cultura. Para as determinações referentes à coloração dos chips, os tubérculos foram divididos ao meio, no sentido transversal, e cortados em fatias de espessura entre 2,5 a $3,0 \times 10^{-3} \mathrm{~m}$, fritando-se apenas as duas fatias centrais para efetuar as determinações. Uma fritadeira industrial (Top Taylor TTF-35-G) foi empregada para a fritura das fatias em óleo vegetal a $180^{\circ} \mathrm{C}$, até cessar o borbulhamento. O tempo médio de fritura foi de três minutos e a temperatura do óleo foi monitorada por termômetro. Após a fritura, foi determinada a coloração dos chips através de um colorímetro digital (Minolta CR-300), efetuando-se duas leituras em cada amostra, com base na metodologia descrita por BLENKINSOP et al. (2002). Os dados foram submetidos à análise de variância e as médias comparadas por regressão polinomial.

Houve efeito significativo das doses de K no crescimento da área foliar da cultura. O índice de área foliar aumentou de 3,21 a 4,44, seguindo uma relação linear (Figura 1A). O número total de tubérculos por planta variou entre 6 e 8 na categoria comercial, e de 14 a 18 na não comercial, sem diferença significativa entre os tratamentos. Os resultados de massa seca e coloração dos chips não apresentaram diferenças significativas (Figura 1B). As médias da massa seca por planta foram de 130,1 e de 108,2 de massa seca total dos tubérculos e da parte aérea, respectivamente. A fração de massa seca correspondente aos tubérculos foi de $83,2 \%$. A produtividade de tubérculos foi de 34,4; 33,2; 29,7; 33,7 e 35,1t ha ${ }^{-1}$ para as diferentes doses de K aplicadas, sem diferenças significativas. A coloração dos chips variou de 59 a 64, sem diferenças significativas (Figura 1C).

Os resultados do efeito de doses de $\mathrm{K}$ na produtividade da batata apresentados na literatura são contraditórios, mostrando a ausência de resposta (DAVENPORT \& BENTLEY, 2001; ABDELGADIR et al., 2003) ou efeitos positivos (WESTERMANN et al., 1994). Essas discrepâncias podem ser atribuídas à composição química do solo, afetando a disponibilidade do nutriente às plantas, ou a teores elevados no solo, acima das necessidades da cultura. Em solos calcários com teores elevados de $\mathrm{Ca}^{++}$e $\mathrm{Mg}^{++}$, a falta de resposta ao $\mathrm{K}$ foi atribuída a interações antagônicas entre os três elementos (JAMES et al., 1994). A ausência de resposta foi associada a teores de $\mathrm{K}$ disponível no solo superiores a $200 \mathrm{mg} \mathrm{L}^{-1}$ (ABDELGADIR et al., 2003). Respostas positivas na produtividade foram obtidas em culturas conduzidas em solos com baixos teores desse elemento e com adubação balanceada (WESTERMANN et al., 1994). Neste experimento, a falta de resposta do K na 


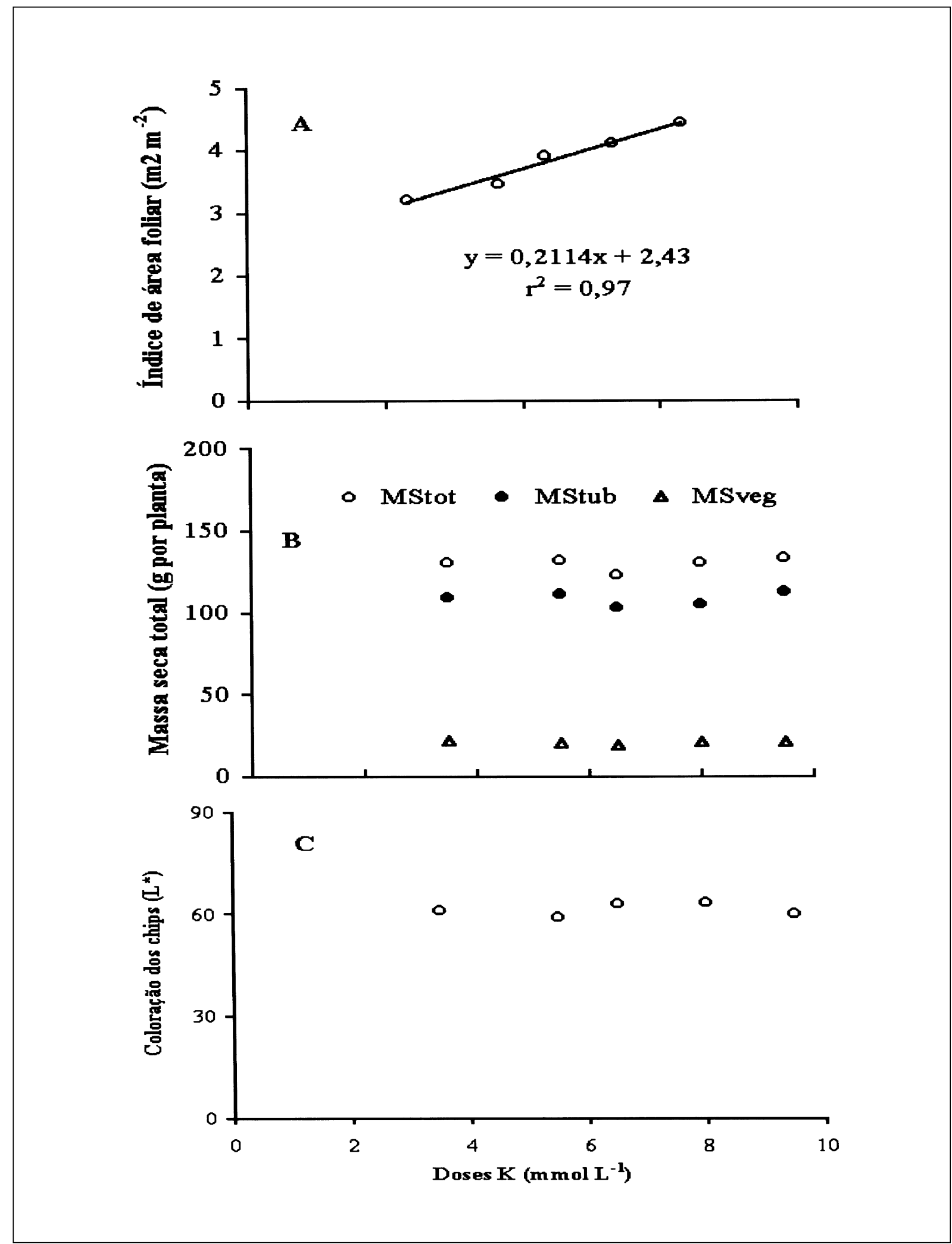

Figura 1 - Índice de área foliar (A), massa seca total (MStot), de tubérculos (MStub) e da parte aérea (MSveq) (B) e coloração dos chips (C) da cultivar Asterix de batata produzida sob doses de K de 3,5; 5,0; 6,5; 8,0 e 9,5mmol L-1 na solução nutritiva. Santa Maria, UFSM, 2004.

Ciência Rural, v.36, n.3, mai-jun, 2006. 
produtividade pode ser atribuída a níveis de disponibilidade acima das necessidades das plantas de batata. As quantidades de $\mathrm{K}$ disponibilizadas para cada planta através do substrato e do volume das soluções nutritivas fornecidas foram de 3.021; 3.540; 3.801; 4.192 e $4.582 \mathrm{mg}$ por planta em cada tratamento. Caso o experimento tivesse sido realizado empregandose solo com teor de $\mathrm{K}$ da ordem de $180 \mathrm{mg} \mathrm{kg}^{-1}$, considerado muito alto pela COMISSÃO DE QUÍMICA E FERTILIDADE DO SOLO (2004), a quantidade disponível para cada planta teria sido de $252 \mathrm{mg}$ por planta. Isso significa que as disponibilidades de $\mathrm{K}$ pelos tratamentos situaram-se entre 12 e 18 vezes acima daquela de um solo com teores muito altos.

Os níveis de $\mathrm{K}$ induziram efeito positivo sobre a área foliar, a qual aumentou linearmente com as doses fornecidas (Figura 1A). Esse resultado é surpreendente, uma vez que o crescimento da área foliar das culturas tem sido relacionado com a disponibilidade de nitrogênio. Uma das funções do K na planta está associada com o transporte dos assimilados (SHABALA, 2003). Esse processo explicaria a influência do $K$ no crescimento de órgãos de acumulação e reserva como os tubérculos, pois estes atingiram uma proporção de $80 \%$ da massa seca total ao final do ciclo de crescimento e desenvolvimento da cultura. Entretanto, o fluxo do K nas folhas poderia ter sido influenciado indiretamente pelo crescimento dos tubérculos, pois existem indicações na literatura de que a taxa de absorção mineral pelas raízes não seria suficiente para atender a demanda de nutrientes decorrente da taxa de crescimento dos órgãos de acumulação e reserva. A diferença entre essas taxas seria tanto maior quanto menor a disponibilidade de nutrientes ao redor das raízes. O déficit de nutrientes decorrente dessa diferença seria suprido pela remobilização da parte vegetativa da planta. Maiores quantidades de $\mathrm{K}$ disponíveis para as raízes reduziriam a remobilização, aumentando a duração do período de vida das folhas, conforme observações anteriores feitas em outras espécies (LE BOT et al., 1994). Entretanto, mesmo com teores disponíveis de $\mathrm{K}$ em todos os tratamentos em níveis superiores àqueles considerados muito altos, houve efeito no crescimento da área foliar. Isso significa que o fornecimento do nutriente via solução nutritiva facilitaria a absorção pelas raízes, confirmando uma das vantagens da fertirrigação como método de adubação.

\section{AGRADECIMENTOS}

Ao Conselho Nacional de Desenvolvimento Científico e Tecnológico (CNPq), pela Bolsa de Produtividade em Pesquisa ao Professor Jerônimo Luiz Andriolo e pela bolsa de Iniciação Científica ao Acadêmico de Agronomia Orcial Ceolin Bortolotto.

À Fundação de Amparo a Pesquisa do Estado do Rio Grande do Sul (FAPERGS), pelo apoio financeiro, processo 01/1704,5.

\section{REFERÊNCIAS}

ABDELGADIR, H.A. et al. The effect of different levels of additional potassium on yield and industrial qualities of potato (Solanum tuberosum L.) in an irrigated arid region. American Journal of Potato Research, v.80, p.219-222, 2003.

BLENKINSOP, R.W. et al. Changes in compositional parameters of tubers of potato (Solanum tuberosum) during low-Temperature storage and their relationship to chip processing quality. Journal of Agricultural and Food Chemistry, v.50, p.4545-4553, 2002.

COMISSÃO DE QUÍMICA E FERTILIDADE DO SOLO. Manual de adubação e calagem para os estados do Rio Grande do Sul e Santa Catarina. 10.ed. Porto Alegre: Sociedade Brasileira de Ciência do Solo, 2004. 400p.

DALSASSO, L.C.M. et al. Consumo de água do tomateiro tipo salada em estufa plástica. Revista Brasileira de Agrometeorologia, v.5, n.1, p.61-67, 1997.

DAVENPORT, R.J.; BENTLEY, M.E. Does potassium fertilizer form, source, and time of application influence potato yield and quality in the Columbia basin? American Journal of Potato Research, v.73, p.311-318, 2001.

JAMES, W.D. et al. Nitrogen and potassium fertilization of potatoes: evaluating nutrient element interactions in petioles with response surfaces. American Potato Journal, v.71, p.249-265, 1994.

LE BOT, J. et al. Plant mineral nutrition in crop production. In: BASRA, A.S. Mechanism of plant growth and improved productivity. Ludhiana, India: Marcel Dekker, 1994. p.3372 .

SHABALA, S. Regulation of potassium transport in leaves: from molecular to tissue level. Annals of Botany, v.92, p.627634, 2003.

WESTERMANN, T.D et al. Nitrogen and potassium fertilization of potatoes yield and specific gravity. American Potato Journal, v.71, p.417-431, 1994.

YORINORI, G.T. Curva de crescimento e acúmulo de nutrientes pela cultura da batata cv. Atlantic. 2003. 79f. Dissertação (Mestrado em Agronomia) - Programa de Pósgraduação em Agronomia, Escola Superior de Agricultura "Luiz de Queiroz” Universidade de São Paulo, Piracicaba. 